This is not the version of record. To access the published version: Tavri, Purva (2019) A successive proenvironmental behaviour framework. Proceedings of the Institution of Civil Engineers - Waste and Resource Management, 172(1), pp. 14-27 see https://doi.org/10.1680/jwarm.18.00005 


\section{A successive pro-environmental behaviour framework}

Purva Tavri

Faculty of Arts, Design and Architecture, Kingston University

Purva Tavri is a $\mathrm{PhD}$ researcher at Kingston University

Email: purvatavri@gmail.com 


\section{Abstract}

This paper presents a successive pro-environmental behaviour framework based on four key models that develop a common argument that, in instances where communicating information is insufficient for triggering and maintaining changes in behaviour, other strategies are needed. These four models are the 'theory of planned behaviour' framework of Ajzen and Fishbein (1980), a model of proenvironmental behaviour by Kollmuss and Agyeman (2002), a conceptual model for recycling behaviour change by Valle et al. (2005), and Stern's (2000) value-belief-norm model.

The resultant pro-environmental behaviour framework has been used as an analytical tool to inform the methodology, and for carrying out the empirical work to investigate re-use behaviour at the organisational level in the UK. The framework is developed by analysing broad areas of argument in relation to pro-environmental behaviour: how it is developed and how it can be maintained.

This paper presents the combination of snowballing and an inductive approach as appropriate methods utilised respectively for the selection of studies, and the development of the successive proenvironmental framework.

The successive pro-environmental framework is called Communication, Engagement/Action, Behavioural Maintenance, and Avoidance of the value action gap (CEBA).

Keywords: Environment, Recycling and re-use of materials, Corporate responsibility

\section{Introduction}

This paper obtains the Kollmuss and Agyeman's definition of pro-environmental behaviour, which means 'behaviour that consciously seeks to minimize the negative impact of one's action on the natural and built world (e.g. minimize resource and energy consumption, use of non-toxic substances, reduce waste production).' (2002, p. 240).

With the focus of developing the framework for investigating re-use behaviour at the organisational level, this paper takes the stance proffered by Bell, Greene and Fisher that 'many seem to think that solving our environmental problems requires only the right technologies. In contrast, relatively less attention has focused on strategies for preserving the environment that involves changes in people's behaviour' (2001, p. 469).

This paper aims to identify two broad areas of argument around pro-environmental behaviour: how it is developed and how it can be maintained. 


\section{Literature review}

Communication, engagement/action, behavioural maintenance, and avoidance of the value action gap are the identified four main dimensions that can aid in investigating the mechanisms required to facilitate and maintain re-use behaviour at the organisational level to make it a behavioural norm.

Rimal and Real define behavioural norms as 'codes of conduct that either prescribe or proscribe behaviours that members of a group can enact' (2003, p. 185). They also regard them as social norms; therefore, they cannot exist without communication between group members. Furthermore, they divide social norms into descriptive and injunctive categories.

Descriptive norms are defined as what people do (Cialdini et al., 1990). Thogersen (2006) describes descriptive norms as consisting of perceptions of normal behaviour. In contrast, injunctive norms are defined by Cialdini et al. as 'rules or beliefs as to what constitutes morally approved and disapproved conduct.' Essentially, 'injunctive norms specify what ought to be done' (Cialdini et al., 1990, p. 1015).

Some of the studies on normative messaging represent messaging appealing to descriptive and injunctive norms are an important factor in facilitating behaviour change (Cialdini et al., 1990; Cialdini, 2003; Cialdini et al., 2006; Kallgren et al., 2000; Schultz et al., 2007; Thogersen, 2006). Nevertheless, there are four key models that develop a common argument that, in instances where communicating information is insufficient for triggering and maintaining changes in behaviour, other strategies are needed. These four models are the 'theory of planned behaviour' framework of Ajzen and Fishbein (1980), a model of pro-environmental behaviour by Kollmuss and Agyeman (2002), a conceptual model for recycling behaviour change by Valle et al. (2005), and Stern's (2000) value-belief-norm model. However, all of these models fail to provide strategies for avoiding the value action gap, which is a barrier to transforming intentions or attitudes into habits or normative behaviours. This barrier of complexity is not limited to the behaviour of individuals, but also has a consequent effect at the organisational level. This is because organisational and individual behaviour patterns are intertwined, as an organisation is made up of individuals. Nonetheless, these models present the effectiveness of salient environment, which indicates that investigating the re-use behaviour of selected organisations, identified as being in the vanguard of promoting environmental activities, could demystify this barrier, as the organisations can be considered to represent a pro-environmental salient environment.

The framework is 'successive' because it is succeeding the models mentioned above. In so doing, the framework acknowledges the factors facilitating behaviour change identified by the aforementioned models and also presents an additional category to fill the identified value action gap.

\section{Method}

To develop the successive pro-environmental framework, 75 pieces of pro-environmental behaviour literature were reviewed, consisting of 40 empirical studies and 35 theoretical studies. These pieces of literature are coherent as they were selected via snowball sampling. 


\subsection{Snowball Sampling}

Lecy and Beatty (2012) present a method of structured literature review in which selection of studies through snowball sampling ensures that the sample contains key publications in the field. They claim that this method serves 'to correct potential bias in unstructured literature reviews and to provide a way to create a parsimonious representation of the most salient research in a field' (Lecy and Beatty, 2012, p. 13).

In this method, construction of the sample is based upon a selection of 'seed articles' (Lecy and Beatty, 2012). The seed articles selected were: Ajzen and Fishbein (1980); Campbell (2007); Cialdini et al. (2006); Cox et al. (2010); Fielding et al. (2008); Groot and Steg (2007); Kallgren et al. (2000); Rimal and Real (2003); Robinson and Read (2005); Thogersen (2006); Valle et al. (2005). From these 11 seed articles, another 64 studies were selected. First, 41 studies citing the seed studies were selected. Then, a further 23 studies that cited the studies citing the seed articles were selected.

Lecy and Beatty state that an advantage of selection of studies through snowball sampling is that 'it adds value by minimising the possible biases associated with cognitive mapping and enables testing hypotheses about actual citation patterns within a given research domain'. However, they acknowledge that this technique is limited to the 'citation patterns and provides little insight into the theoretical content' of the selected studies (2012, p. 2).

Adopting snowball sampling enables selection of studies or theories that are consistent, which according to Marsh and Stoker (1995) can contribute to develop a firm framework that is formed by the selection of the studies with relevant empirical evidence and not solely grounded in observed cases that provide 'anecdotal' theoretical claims.

For developing the framework, some key methodological studies were reviewed to shed light on grounded theory. These studies were Gersick (1988); Glaser and Strauss (1967); Locke (2001); Marsh and Stocker (1995); Mills and Briks (2014) that indicated inductive approach as an integral part of the grounded theory, which brings fresh perspectives and new theories, enlivening and modifying existing theoretical frameworks. This, in particular, is a key element that falls in line with the purpose of investigation. Thus, the successive pro-environmental framework is developed using an inductive approach.

\subsection{The Inductive Approach}

The inductive approach involves establishing upper-level, lower-level and main categories, which constitute the whole framework through coding and grouping textual materials (Elo and Kyngas, 2007; Locke, 2001; Mayring, 2000; Thomas, 2003).

In his work on the general inductive approach for analysing qualitative data, Thomas (2003) used raw textual data to form links in order to derive findings. According to him, the first step is extracting the core meaning evident in the text that is relevant to the research objective; in an inductive approach, 
this is forming 'upper-level categories'. Secondly, the extracted textual information is divided into themes or categories, which are known as 'lower-level categories'. Finally, the produced themes or categories are further analysed to develop the 'main categories'.

As per Thomas's (2003) approach, the selected pro-environmental behaviour studies were grouped together and collated using Microsoft Excel and were separated out for the purpose of analysis. They are divided into study type, location, participants, size, situation, method, findings, and conclusion.

The 'upper-level categories' were formed through an initial review of the selected pro-environmental behaviour studies. This involved selecting as many headings as seemed relevant for the establishment of the framework.

Table 1 below shows the terms that were identified based on the number of instances with which the terms and their meaning appeared in the similar context during the initial review. After that, the 'lowerlevel categories' and the 'main categories were formed which is elaborated next.

Table 1: Upper-level categories derived from an initial review of pro-environmental behaviour studies

\begin{tabular}{|l|l|l|}
\hline Situational norm & Informational social influence & Self-awareness \\
\hline Persuasion & Resource and technology & Regulation and policy \\
\hline Value action gap & Government system & Sustainable \\
\hline Ethical behaviour & Ethical responsibility & Social norm \\
\hline Misperception & Boomerang effect & Identity relevance \\
\hline Subjective norm & Automatic social perception & Stereotypes \\
\hline Personality traits & Associative strength & Attitude change \\
\hline
\end{tabular}

The 'lower level categories' are here referred to as 'variables', and the 'main categories' are called 'categories'.

These variables and categories were formed according to my perception and analysis of the studies. Such an approach is susceptible to bias. Nevertheless, the combination of snowball sampling, and the inductive approach can be considered as playing a part in selecting coherent studies and bringing a fresh perspective by enlivening and modifying existing pro-environmental behaviour studies (Locke, 2001; Lecy and Beatty, 2012; Marsh and Stoker, 1995), which this paper accounts as contributing towards overcoming biases.

\section{The Theoretical Framework}

The categories in the successive pro-environmental framework are communication, engagement/action, behavioural maintenance, and avoidance of the value-action gap, or CEBA for short. The following sections explain the formation of variables and categories through review and analysis of the selected pro-environmental behaviour studies. 


\subsection{Communication (C)}

This section explores the selected studies that indicate 'communication' as an important factor for facilitating behaviour change. In so doing, the section forms 'lower-level categories' or 'variables' by analysing and drawing out the themes from the selected studies.

The formation of variables within this category draws directly on Kelman's (1958) study on the types of communication, whereby, he reports the experiment carried out from a broader theoretical framework that analysed different processes of attitude change resulting from social influence. In his study, Kelman delineates high power communication, that can contribute to lasting change in individuals' attitudes and beliefs, and low power communication, which leads only to superficial and short-lived changes.

Since the investigation aims to evaluate re-use behaviour longevity, only high types of communication have been used as variables. They are high means control, high attractiveness, and high credibility. The current relevance of this sixty-year-old study (Kelman, 1958) is validated by presenting compatibility of Kelman's types of high power communication with the relatively recent behaviour studies in Table 2 featuring communication as a crucial category in promoting behavioural change.

Table 2: Studies featuring communication as a crucial category

\begin{tabular}{|l|l|}
\hline Cashore and Vestinsky (2000) & Schultz et al. (2007) \\
\hline Cialdini (2003) & Stern (2000) \\
\hline Gockeritz et al. (2010) & Thaler and Sunstein (2009) \\
\hline Kagan et al. (2003) & Thogersen (2007) \\
\hline Lindenberg and Steg (2007) & Thomas et al. (2004) \\
\hline Mannetti et al. (2004) & Valle et al. (2005) \\
\hline Rimal and Real (2003) & Wenzel (2005) \\
\hline
\end{tabular}

The section below discusses the studies featuring the first variable under the communication category, high means control.

\subsubsection{The first variable (high means control)}

In his study, Kelman (1958) represented influence through mandatory rules and regulations as 'high means control'. He identifies 'high means control' with compliance, writing that:

compliance can be said to occur when an individual accepts influence because he hopes to achieve a favorable reaction from another person or group. He adopts the induced behaviour, not because he believes in its content, but because he expects to gain specific rewards or approval and avoid specific punishments or disapproval by conforming. Thus the satisfaction derived from compliance is due to the social effect of accepting influence (1958, p. 53).

In their study on framing the responsibility for strategic leadership of ethical behaviour in businesses, Thomas, et al. (2004) indicate that the initiative for ethical change needs to originate from the leaders within the organisation. They suggest that behaviour can be enforced by leaders who strengthen and 
communicate ethical values throughout an organisation. They present examples such as passing on

the cost of ethical failure via fines, penalties, legal investigations, and a potential threat to the reputation of the business.

The importance of enforcement for maintaining organisations' reputations, through governance systems, regulation, and environmental policy is also emphasised by Cashore and Vestinsky (2000) in their study of influencing corporate behaviour. They looked at three forestry organisations in British Columbia, Alberta, and Alabama, and concluded that 'firms try to accommodate state officials' interests when they know decisions may be taken that could affect firms' operations' (2000, p. 10).

One way of facilitating pro-environmental behaviour change is by establishing compliance. Within the waste management sector, duty of care is one of the legislative regimes established in the UK under the Environmental Protection Act 1990, followed by various waste directives. Duty of care and the waste directives form part of the UK waste strategy for moving up the waste hierarchy and achieving zero waste to landfill. Therefore, in investigation, the empirical study used waste hierarchy and zero waste to landfill as the elements to measure compliance among organisations.

The following section examines the studies featuring the second variable within the communication category, high attractiveness.

\subsubsection{The second variable (high attractiveness)}

Kelman (1958) defines 'high attractiveness' as an individual's identification within a group, and says that:

identification can be said to occur when an individual accepts influence because he wants to establish or maintain a satisfying self-defining relationship to another person or a group. This relationship may take the form of classical identification, in which the individual takes over the role of the other, or it may take the form of a reciprocal role relationship. The individual actually believes in the responses which he adopts through identification, but their specific content is more or less irrelevant. He adopts the induced behavior because it is associated with the desired relationship. Thus the satisfaction derived from identification is due to the act of conforming as such (1958, p. 53).

Wenzel (2005) conducted a study with 64 students of an Australian university, who believed that taxpayers should show more honesty in their tax affairs than they believed people do under the current system. At the same time, Wenzel also carried out a similar study at the household-level investigating the perceptions of 1,500 Australians on paying taxes. In both scenarios, the participants were provided with feedback about the actual number of taxpayers, which was more than the participants perceived. This feedback changed the perception of the participants about taxpayers, thus leading to mass persuasion. This paper notes that such form of intervention through feedback could be considered as enabling development of identification via obtaining 'a satisfying self-defining relationship to another person or a group' (Kelman, 1958, p. 53). 
Wenzel (2005) further stated that this form of communication through feedback could also be successful in the field of environmental behaviour and health. The significance of feedback in the field of environmental behaviour is indeed demonstrated by Vlek (2000) in his study, whereby, he surveyed different levels and global impact of major environmental problems. In his study, Vlek identified six lines of environmental psychological research ranging from environmental attitudes to environmental policy decision support system. Vlek concluded that communicating feedback is an essential factor contributing to preventing environmentally harmful behaviours because lack of regular feedback about environmental issues could cause ignorance and lack of attention towards environmental problems. This according to him may further lead to 'gullibility, helplessness, and apathy' (2000, p. 162).

Along similar lines, Thaler and Sunstein's (2009) study on 'nudge', which found that one way in which a shift in behaviour can be achieved is simply by informing people about the performance of others. They said that 'sometimes the practices of others are surprising, and hence people are much affected by learning what they are' (2009, p. 71).

External or contextual forces including interpersonal influences and community expectations are also highlighted by Stern (2000) as significant factors contributing to behavioural change. This is also supported by an empirical study of pulp and paper manufacturers in British Columbia, Canada, Australia, New Zealand, Washington, and Georgia by Kagan et al. (2003). The study found that concerns expressed by environmental groups against pollution led to a change in behaviour within organisations, since 'environmental activists can intensify economic pressures by generating adverse publicity about polluting firms and organising consumer boycotts' (2003, p. 68).

Thaler and Sunstein (2009) argue that peer pressure, and internal and external feedback are among the crucial factors contributing to social influence in the field of decisions about health, wealth, and happiness. They observe that 'social influences come in two basic categories. The first involves information. The second involves peer pressure' (2009, p. 58).

One recent successful example is the increase in the use of seat belts in Montana through the 'Most of Us Wear Seatbelts Campaign'. This campaign was aimed at reframing seatbelt use as a social norm. Owing to the success of the campaign, the self-reported use of seat belts increased significantly, thereby making it a norm (Linkenbach and Perkins, 2003).

Discussing the importance of relating pro-environmental behaviour with positive social identities in campaigns, Mannetti et al. in their study on identifying behavioural intentions concerning household recycling concludes 'identity as an antecedent of pro-environmental behaviour [that] provides a broader perspective to persuasion campaigns' (2004, p. 234). The study surveyed 230 Italians, whereby a questionnaire concerning opinions about household recycling behaviour was administered. The result suggested that one of the ways in which households could be influenced towards the use of refuse collection and disposal facilities is via campaigns portraying recycling behaviour as prestigious, and anti-environmental behaviour as "out-of-fashion". 
To analyse organisations' ways of gathering internal and external responses to their environmental and re-use activities, the investigation used feedback and comparative analysis as assessment tools. The next section reviews the studies providing evidence of the third variable in the communication category, high credibility.

\subsubsection{The third variable (high credibility)}

Influence through knowledge and facts, is designated 'high credibility' by Kelman (1958). In this study three indicators of high credibility are used: achievements, guidelines, and innovation. Kelman describes 'high credibility' as internalisation, noting that:

internalization can be said to occur when an individual accepts influence because the content of the induced behavior - the ideas and actions of which it is composed - is intrinsically rewarding. He adopts the induced behavior because it is congruent with his value system. He may consider it useful for the solution of a problem or find it congenial to his needs. Behavior adopted in this fashion tends to be integrated with the individual's existing values. Thus the satisfaction derived from internalization is due to the content of the new behavior (1958, p. 53).

Schultz et al. (2007) conducted an experiment on 290 households in San Marcos, California, USA. The purpose of the study was to increase awareness of energy usage among households. The study highlights the importance of the method of presentation of a message for its effectiveness in changing behaviour. When consumers were supplied with a descriptive normative message, giving facts about consumption, this created a boomerang effect, resulting in an increase in consumption. In contrast, when the same message was supplied in an injunctive normative form, by providing a happy smiley (to those who consumed less) and sad smiley (to those who consumed more), this eliminated the boomerang effect and resulted in less energy consumption.

A two-year study was conducted by Gockeritz et al. (2010) of 1,604 residents in California. The purpose was to assess whether normative social influence is moderated by personal involvement and injunctive normative beliefs. The results showed that facts and personal beliefs play a significant role in influencing behaviour. The study concluded that when communicating messages to groups or individuals, the greatest impact on behaviour comes from a combination of descriptive and injunctive normative information.

In 2003, Cialdini carried out a study demonstrating the influence of messages providing information on individual behaviour. He observed visitors at Arizona's Petrified Forest National Park over five consecutive weekends. Around one ton of wood was stolen from the park by visitors every month. To modify attitudes to theft, an injunctive message was displayed at entrances and exits, saying 'Please don't remove the petrified wood from the Park, in order to preserve the natural state of the Petrified Forest.' This message was accompanied by 'a picture of a lone visitor stealing a piece of wood, with a red circle and bar symbol superimposed over his head' (Cialdini, 2003, p. 107). The result led to the 
decrease in thievery and this outcome of the study illustrates that providing knowledge in an injunctive normative message is effective in a situation characterised by socially reprehensible conduct.

These studies suggest that behaviour is more likely to change when messages are delivered in a way that positively emphasises socially acceptable behaviour, rather than focussing on what might be perceived as draconian rules and regulations. This is further indicated by Lindenberg and Steg (2007) in their study on guidance regarding environmental behaviour, which suggested that in order to motivate normative behaviour, knowledge and awareness of the impact associated with the behaviour are among the important elements that need consideration.

The studies reviewed above demonstrate the utilisation of descriptive normative messages, namely, facts, evidence, and information, alongside injunctive normative messages, consisting of rules and beliefs about what is morally acceptable. Both types of message can play a part in identifying and evaluating the capacity of re-use activities to attain strong sustainability at the organisational level.

How a message is communicated can determine its success or failure in changing behaviour. For instance, in the studies discussed above, the simultaneous use of descriptive and injunctive messages helped avoid the boomerang effect as the content of the messaging intended to harmonise the messaging with individuals or organisations value system, which this thesis notes could lead to internalisation.

Although the variables - high means control, high attractiveness and high credibility are represented separately in Figure 1 below, in reality there is a complex interrelationship between them. In the reallife investigation of re-use behaviour, how variables are utilised can vary depending on the type of organisations.

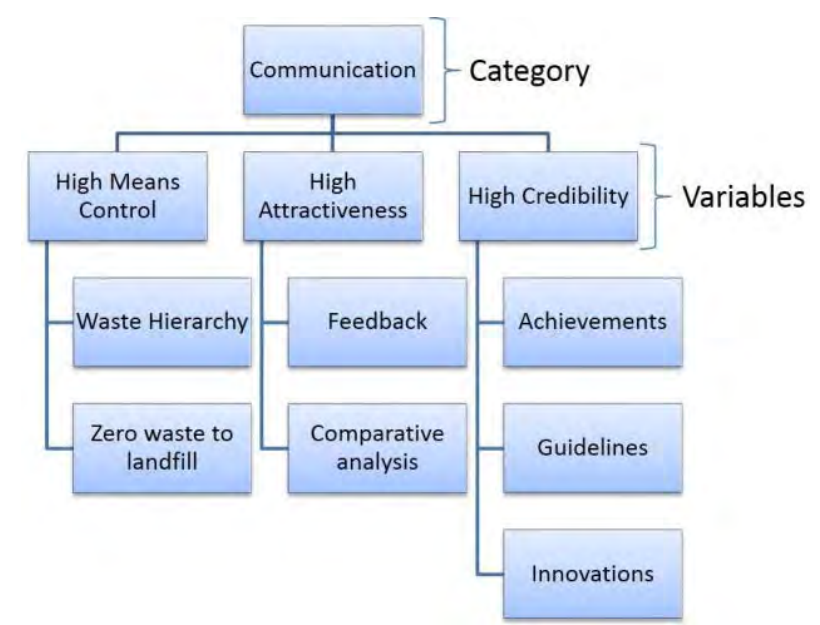

Figure 1: Communication variables, formed by sorting and grouping the upper-level categories

The communication category and variables can help to facilitate behaviour change, by affecting the ways in which individuals view themselves and their place within a wider group. Nevertheless, in their study of the influence of perceived norms, Rimal and Real (2003) found that communicating a norm is one thing, but creating action based on that norm is much more complex. As they put it, 'individuals 
may perceive high levels of prevalence and strong normative pressures and yet not engage in the behaviour' (2003, p. 187).

The fact that the communication category alone is insufficient to drive sustained change indicates a gap, which Rimal and Real (2003) suggest can be filled by activating the norm: essentially acting upon the given communication. The section below elaborates the ways in which a norm is activated, by engaging or acting upon it.

\subsection{Engagement/Action (E)}

This section explores those pro-environmental studies that feature engagement/action as an important category in behaviour change. In doing so, the section forms 'lower-level categories' or variables by analysing and drawing out themes from the following behaviour studies in Table 3 .

Table 3: Studies featuring engagement/action as a crucial category

\begin{tabular}{|l|l|l|}
\hline Aarts et al. (2003) & Dolan et al. (2012) & Peng and Chiu (2010) \\
\hline Aarts and Dijksterhuis (2003) & Goldstein et al. (2008) & Prendergrast et al. (2008) \\
\hline Bargh and Ferguson (2000) & Groot and Steg (2009) & Rothman (2000) \\
\hline Barr et al. (2001) & Kallgren et.al. (2000) & Steg and Vlek (2009) \\
\hline Campbell (2007) & Kelman (1958) & Thogersen (2006) \\
\hline Cialdini et al. (1990) & Kong et al. (2002) & Thogersen (2007) \\
\hline Collier and Esteban (2007) & Lachman et al. (1994) & Vermeir and Verbeke (2006) \\
\hline Dewhurst and Thomas (2003) & Nye and Hargreaves (2010) & WRAP (2018j) \\
\hline Dijksterhuis et al. (2000) & Organ et al. (2006) & \multirow{2}{*}{ Zhang (2011) } \\
\hline Dijksterhuis and Bargh (2001) & Payne and Raiborn (2001) & \\
\hline
\end{tabular}

The following section surveys the studies providing evidence of the first variable under engagement/action, namely, non-economic variables.

\subsubsection{Non-economic variables}

The non-economic variables identified here are situational norms, social context, and salient environment that studies below indicate facilitates shared goal seeking and play a part in developing an associative strength and cooperative type of behaviour. However, these non-economic variables are interdependent and thus cannot be represented in a sequential manner.

Cialdini et al. (1990) conducted a study on the impact of norms, involving an experiment on 139 visitors at the parking garage of a university-affiliated hospital. Visitor behaviour within both heavily littered and clean parking areas was observed for six days. Leaflets were dropped by visitors in the littered environment, but not in the clean environment. The study concluded that focus of attention and/or the salient environment were important components inclining individuals towards a course of action.

Along similar lines, Kallgren et al. (2000) conducted a study on 107 psychology students at Arizona State University to examine categories that might affect the relationship between norm focus and behaviour. In the university, corridors and stairs were pre-littered and different norms were displayed; 
some anti-litter norms were very specifically related to the university and its environment, and some gave more general anti-littering messages. Participants were found to be less inclined to litter in a corridor displaying an anti-litter norm that was specifically related to their environment. Therefore, the results show that a norm has a greater impact on behaviour when it is salient to the surrounding.

This positive effect associated with messages that are specific to the surrounding area was also found by Aarts and Dijksterhuis (2003); Aarts et al. (2003); Dewhurst and Thomas (2003); Dolan et al. (2012); Nye and Hargreaves (2010); Steg and Vlek (2009); Thogerson (2006); Thogerson (2007); Thomas (2003); Vermeir and Verbeke (2006) in their individual and organisational studies.

These studies indicate that encouraging action towards shared goals is the key to converting communication into action. Specifically, when a goal is agreed, habitual plans or actions in order to achieve that goal are automatically activated (Bargh and Ferguson, 2000). In this way, a collective goal can change individual attitudes and behaviour, and therefore lead to a wider transformation within the group.

This point is further emphasised with the example of the 'Planet Earth // effect', which resulted in the formation of a collective goal in the UK of reducing plastic pollution through the UK Plastics Pact ${ }^{1}$ (WRAP, 2018j). So far, 96 businesses from across the entire plastics value chain have signed up to this shared goal.

\subsubsection{Associative strength (cooperative behaviour)}

It is contended that activating shared goal seeking, automatically elicits certain behaviours that develop the associative strength (Collier and Esteban, 2007). Associative strength is a condition that is critical for enabling normative behaviours to develop and be maintained (Kong et al., 2002). Attaining an associative strength is further indicated as building a cooperative behaviour (Collier and Esteban, 2007).

Cooperative behaviour is defined by Organ et al. in their study of organisational citizenship behaviour as 'individual behaviour that is discretionary, not directly or explicitly recognized by the formal reward system, and in the aggregate promotes the efficient and effective functioning of the organization' (2006, p. 3). In his previous study, Organ defined associative strength as 'performance that supports the social and psychological environment in which task performance takes place' (1997, p. 95).

Peng and Chiu (2010), in their study examining the underlying cooperative relationship between supervisor and employee, indicate that cooperative behaviour within an organisation aids in effective productivity, coordinating team members to enable effective performance towards the enhancement of resources. Furthermore, Zhang, (2011) in his study of cooperative organisational behaviour,

\footnotetext{
1 The UK Plastics Pact aims to transform the UK plastic packaging sector by 2025 by aiming for ' $100 \%$ of plastic packaging to be re-usable, recyclable or compostable; $70 \%$ of plastic packaging effectively recycled or composted; take actions to eliminate problematic or unnecessary single-use plastic packaging items through redesign, innovation or alternative (re-use) delivery models; and 30\% average recycled content across all plastic packaging.' (WRAP, 2018j)
} 
provides evidence that this type of behaviour is encouraged by giving feedback on performance that

is not limited to economic benefits, but also places value on instances where employees have travelled 'the extra mile'. Kelman (1958) describes this as the adoption of a value system by a group that influences others to cooperate within this value system, in order to receive a favourable reaction from the group.

In their pro-environmental behaviour study, Bargh and Ferguson (2000) indicate that a cooperative situation automatically activates the norms that then guide intergroup behaviour towards the shared goal. Zhang (2011) further states that at the organisational level, cooperative behaviour provides evidence of growth in productivity, efficiency, and customer satisfaction.

Associative strength implies a cooperative behaviour that facilitates cohesion within the organisation, which is also evident at the household level. Barr et al. (2001), in their analysis of recycling behaviour in Exeter, show the formation of cooperative behaviour among households, which, over time, contributed to sustained behaviour change. Barr et al. (2001) developed three predictors of cooperative behaviour: environmental values, situational variables, and psychological variables. The study concluded that environmental values among individuals, along with social pressure to perform in an environmentally-friendly manner, were the two primary forces that built cooperation among households in Exeter. The findings indicate that peer pressure leads to cooperation, and cooperation had a direct impact on waste minimisation among households, which led to sustained behavioural change.

Associative strength develops willingness to act towards a common goal. This can be seen in studies by Campbell (2007), Goldstein et al. (2008), and Payne and Raiborn (2001). Associative strength, as represented in these studies, is a willingness to change current behaviour because of individuals' strong identification with an organisation, which can, in turn, be translated into cooperative behaviour, encouraging them to begin working towards a common goal.

Two very distinct studies, one on moving business towards sustainable consumption behaviour (Kong et al., 2002), and another on employee commitment in an organisation, (Collier and Esteban, 2007) present associative strength as a relevant and useful characteristic that contributes to changing behaviour and maintaining the change.

There is a direct relationship between associative strength and automatic behaviour. Empirical studies by Dijksterhuis et al. (2000) and Dijksterhuis and Bargh (2001) indicate that associative strength functions through communication, which leads to the development of stereotypes. Stereotypes are commonly considered to be negative; however, they can function in a positive way in this instance, by activating associated traits which create real motor change representations (i.e. neurological changes) that in turn trigger reward patterns within the brain, resulting in lasting change in actual behaviour.

\subsubsection{Discussion}

Thus far, we have seen that salient environment, social context, and situational norms can automatically transform communication into action by developing associative strength. In doing so, 
associative strength could bring effective productivity, efficiency, customer satisfaction, cohesion, imitation, and plays a part in making a behaviour into a social norm. Nonetheless, it is important to acknowledge that the associative strength is not inherently positive: in some cases, it may lead to destruction, inefficiency, and unproductiveness, leading to organisations becoming uncaring and defeatist. However, finding the factors that contribute to building associative strength is here considered a positive move, as this will enable re-use behaviour.

Since, the non-economic variables identified here, viz. situational norms, social context, and salient environment, are interdependent and thus, depending on the context, they might not have this transformative effect if applied individually in real-life situations.

To develop associative strength (cooperative behaviour) along with these non-economic variables, availability of resources is a key factors contributing to activation of shared-goal seeking. Thus, the section below presents studies providing evidence for the second variable under the engagement/action category, economic variables.

\subsubsection{Economic variables}

Lachman et al. (1994) in their study on analysing cross-national management and organisations argue that resources and the availability of technology have an important impact on organisations' ability to adapt in response to pressure. Thogersen (2007) in his study on the activation of social norms builds on this argument by indicating that greater availability of resources is an economic benefit, which increases the chance of cooperation and motivates behaviour towards a required goal. In other words, the availability of money or resource incentives motivates not only at the level of individuals, but also across businesses more broadly.

Campbell's (2007) study of corporate social responsibility (CSR) suggests that financially strong companies are more likely to behave in a socially responsible manner. Thus, those companies are more adaptive to behavioural change. Furthermore, in their study investigating the international public policy spectrum to understand the drivers behind people's choices and behaviour, Prendergrast et al. (2008) identify the availability of financial resources as a key driver for influencing behavioural change.

Thus, although the non-economic variables discussed above can significantly elicit behaviour by activating a goal, economic variables, such as the availability of resources, are also important for transforming communication into engagement or action.

Moreover, economic and non-economic variables need to be utilised in real-life situations in a collective manner, as their combination has the power to engage groups or individuals towards proenvironmental behaviour by developing associative strength. Furthermore, although for convenience these variables are represented separately in Figure 2 below, in real-life situations, investigating noneconomic and economic variables facilitating pro-environmental behaviour may vary depending on the type of re-use (waste management) activities within organisations. 


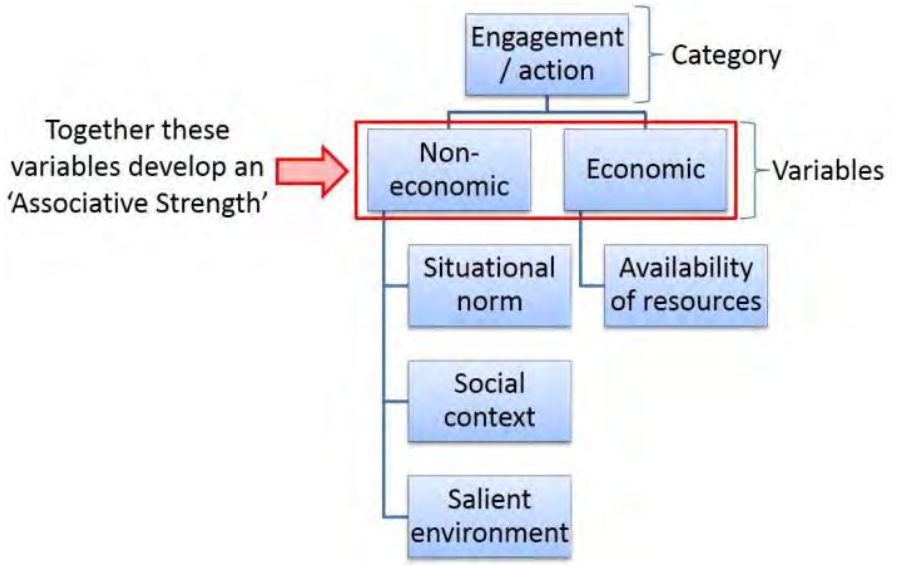

Figure 2: Engagement/action variables, formed by sorting and grouping the upper-level categories

Rothman's (2000) study of behavioural maintenance argues that a link between achieving the goal and encouraging action needs to be developed in order to transform behaviours from new actions to normative and embedded habits. In essence, he means that the newly acquired behaviour needs to be maintained and repeated over time in order to transform it into a habit or a normative behaviour. The section below establishes the importance of maintaining behaviour as another important category for facilitating behaviour change, which was identified in Section 2 above as a factor missing from the existing key pro-environmental models.

\subsection{Behavioural maintenance (B)}

Making a change is one thing, maintaining and monitoring this change requires a more strategic approach. Evaluation of the new behaviour (in the case of re-use: specifically re-starting and maintaining re-use behaviour) depends on an effective monitoring process.

Measuring and monitoring are essential to ascertain that the changed behaviour is maintained to establish it as a normative behaviour (Rothman, 2000). Vlek (2000) argues that regular measuring and monitoring of changed behaviour helps to identify and overcome practical barriers and challenges.

The following behaviour studies discuss behavioural maintenance as a crucial category in behaviour change within individuals, group or organisations: Budeanu (2007); Kanter (1999); Rimal and Real (2003); Rothman (2000); and Vlek (2000).

Kanter, (1999) in his study of organisational innovation through public-private partnership (PPP), concluded that to maintain successful long-term change within organisations, a commitment to change is required, which results in long-term benefits such as job creation in poor communities and high-quality financial services for disadvantaged minorities.

Similarly, in his study of the long-term effects of behaviour-change intervention strategies, Rothman (2000) argues that maintaining behaviour depends on perceived satisfaction with the resultant outcomes. Adopting a new behaviour and embedding it as a habit requires repeated assessment of 
satisfaction levels; individuals within a group also need to know the benefits attached to the change.

He concluded that:

given that the repeated application of intervention strategies that facilitate short-term success does little to improve rates of long-term success, the premise that there are important differences in the psychological processes that govern behavioural initiation and maintenance appears worthy of consideration (2000, p. 65).

Rimal and Real's (2003) study involved 353 undergraduate students from Texas A \& M University in assessing perceived norms. The students were given a computer-based task and asked questions related to smoking and drinking habits. The findings showed that individuals do not simply change their behaviour by mimicking others; rather, they assess the benefits before making decisions.

A study of sustainable tourist behaviour by Budeanu (2007) indicates one of the factors that influence pro-environmental tourist before finalising their holiday is knowing about the sustainable activities that they can carry out at the destination. The study concludes that tourists who have strong proenvironmental belief are identified as willing to change their behaviour while booking holidays if they register a clear intention to benefit the destination. That is; if the destination involves activities such as voluntary holidays, Eco-Tours, the sustainable tourist intends to book these types of holiday destination over those without pro-environmental activities. This is in line with the Groot and Steg (2007) study discussed above on testing the TPB framework with a questionnaire about people's intention to use a park-and-ride facility. Whereby, the result indicates that having an advantage or benefits in using the facility is identified as one of the key factors resulting in the differences of people's intention.

Maintaining change is directly linked to the satisfaction level and benefits attained from the newlyformed behaviour, which is assessed by regular monitoring. Thus, behavioural maintenance, involving measuring and monitoring as variables, is identified as an important category in maintenance of reuse behaviour. Nonetheless, measuring and monitoring can only occur when there is an action to measure, so behavioural maintenance is dependent on engagement/action.

In the empirical study, any data and studies showing evidence of measuring and monitoring is assigned to the behavioural maintenance category, which is represented with its variables in Figure 3 below.

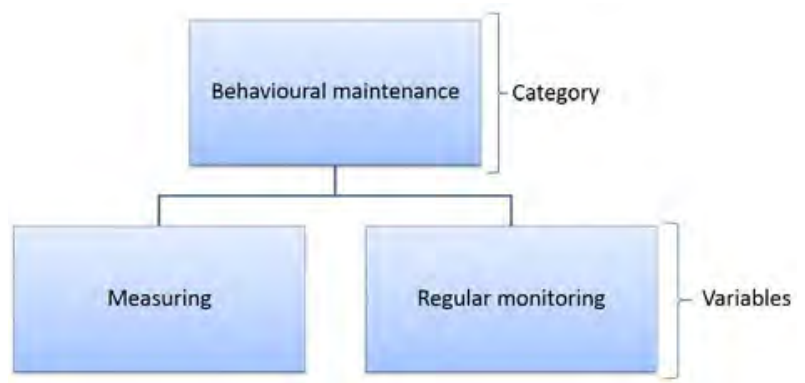

Figure 3: Behavioural maintenance, formed by sorting and grouping the upper and lower level categories 
The communication, engagement/action, and behavioural maintenance categories, when applied together, can be used for instigating behaviour change and its maintenance. Nevertheless, a critical barrier to transforming changed behaviour into a norm, which was identified in the literature review of the key pro-environmental frameworks (Section 3.3.1 above), is the gap between the willingness to act and the actual behavioural change: the value action gap.

It is important to acknowledge that there can be instances where behaviour does not change, as there may still be a gap between intention and actual behaviour. Therefore, minimising the value action gap is another main category of the framework.

\subsection{Avoidance of the value action gap (A)}

The following behaviour studies pertain to avoidance of the value action gap as a crucial category in avoiding the barriers to promoting and maintaining behaviour change within individuals, groups or organisations: Berkowitz (2004); Kaiser et al. (2010); Kollmuss and Agyeman (2002); Pickett-Baker and Ozaki (2008); Prendergrast et al. (2008); Prentice and Miller (1996); and Thaler and Sunstein (2009).

In their study of the influence of marketing on consumer purchase decisions, Pickett-Baker and Ozaki (2008) argue that the value action gap is a phenomenon that tends to develop due to misperceptions. According to them, the value action gap is the difference between beliefs and actual behaviours. They illustrate this with the example that 'an individual concerned about the environment does not necessarily behave in a green way in general, or in their purchasing' (2008, p. 282).

In Section 3.3.1 above, we saw that Kollmuss and Agyeman (2002) concluded that the value action gap is a common cause of failure in pro-environmental behaviour models. They imply that many such models fail to take individual, social, cultural, and economic constraints into account. This is because the models assume that humans are rational beings, who make systematic use of information provided, whereas, in reality, this may not be the case.

Kaiser et al. (2010) conducted a study of an inconsistency between attitude and behaviour, whereby they illustrate that the discrepancy between verbal evaluations and actual behaviour is the cause of several difficulties. Therefore, they concluded that avoiding misperceptions or the value action gap needs to be considered when applying behaviour change studies to real-life practices.

In his study of social norms, Berkowitz (2004) also found that a gap can occur between perceived and actual norms, leading to a misperception. Thus, he argues that 'it is extremely important to determine the most salient and relevant influences on the target group before designing an intervention to make sure that the norms being corrected are influential' (2004, p. 21). Nonetheless, Berkowitz indicates that clear communication, and facilitating engagement could potentially avoid the value action gap. $\mathrm{He}$ explains that because of the lack of clear communication and action on that communication, so-called 'pluralistic ignorance' gets developed. Pluralistic ignorance is 'when a majority of individuals falsely assumes that most of their peers behave or think differently... [about something]...when in fact their attitudes or behaviours are similar' (2004, p. 7). 
Pluralistic ignorance is also discussed by Thaler and Sunstein (2009) in their book, Nudge. They

claim that pluralistic ignorance is a persistent problem in many social practices that must be considered during the behaviour change investigation.

Prendergrast et al. (2008) indicate that if a communicative message is complex, and if there are limitations in an individual's cognitive processes, this could lead to pluralistic ignorance, further contributing to the value action gap. Nonetheless, Prentice and Miller's (1996) study of pluralistic ignorance suggests that to avoid the value action gap, the social norm of changing behaviour must be influential enough to prevent people from being swayed by their private thoughts and opinions. They further argue that social perception is mostly guided by observation; a strong message, therefore, has the power to correct pluralistic ignorance by communicating facts and knowledge to a wider group, thereby shaping that group's attitudes and behaviour. Prendergrast et al. (2008) likewise argue that a powerful and simple message takes individual variability into consideration and therefore acts as an internal drive to avoid the value action gap within a group.

These studies suggest that understanding individual, social, cultural, and economic circumstances, communicating an influential message explicitly and clearly, and engaging or acting upon behaviour are crucial strategies for avoiding the value action gap.

In the empirical study, any data and studies showing evidence of communication, engagement/action, and diversity/CSR, that is social, cultural, and economic circumstances, are assigned to the 'avoidance of the value action gap' category. This facilitates analysis of the factors and barriers organisations face in achieving re-use as a normal activity. Nonetheless, although for the purpose of this study, these variables are represented separately in Figure 4 below, in real-life situations, investigating the factors that can help to avoid the value action gap is much more complex. This is because of the inter-dependency and connectivity among the categories and variables, which will take social, economic, cultural, and technological factors into consideration during the investigation.

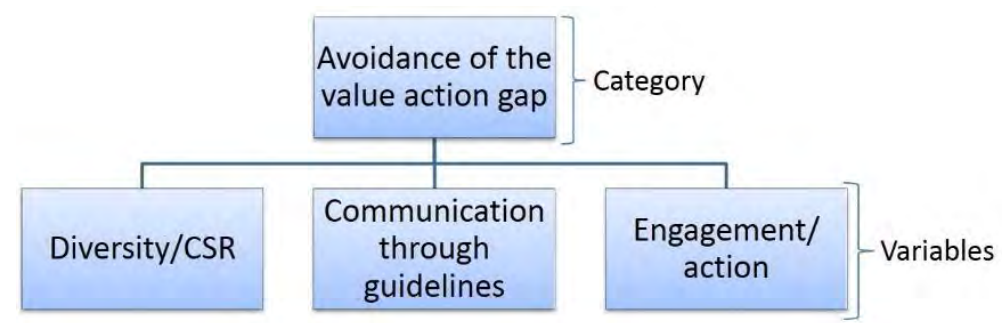

Figure 4: Avoidance of the value action gap, formed by sorting and grouping the upper and lower level categories

\section{Conclusion and Future Study}

It is not enough to simply acquire a new set of beliefs around a principle (such as to re-use). The acceptance of a new value system, leading to decisive and sustained action, requires support and reinforcement of the behaviour, via a variety of means, as illustrated above. 
Figure 5 below presents a schematic diagram of the successive pro-environmental framework, which has been developed in this paper using snowballing and the inductive method to select and analyse pro-environmental behaviour studies.

Figure 5 shows communication, engagement/action, behavioural maintenance, and avoidance of the value action gap as the key categories that will be used for investigating re-use behaviour at the organisational level. This successive pro-environmental framework is called 'CEBA'.

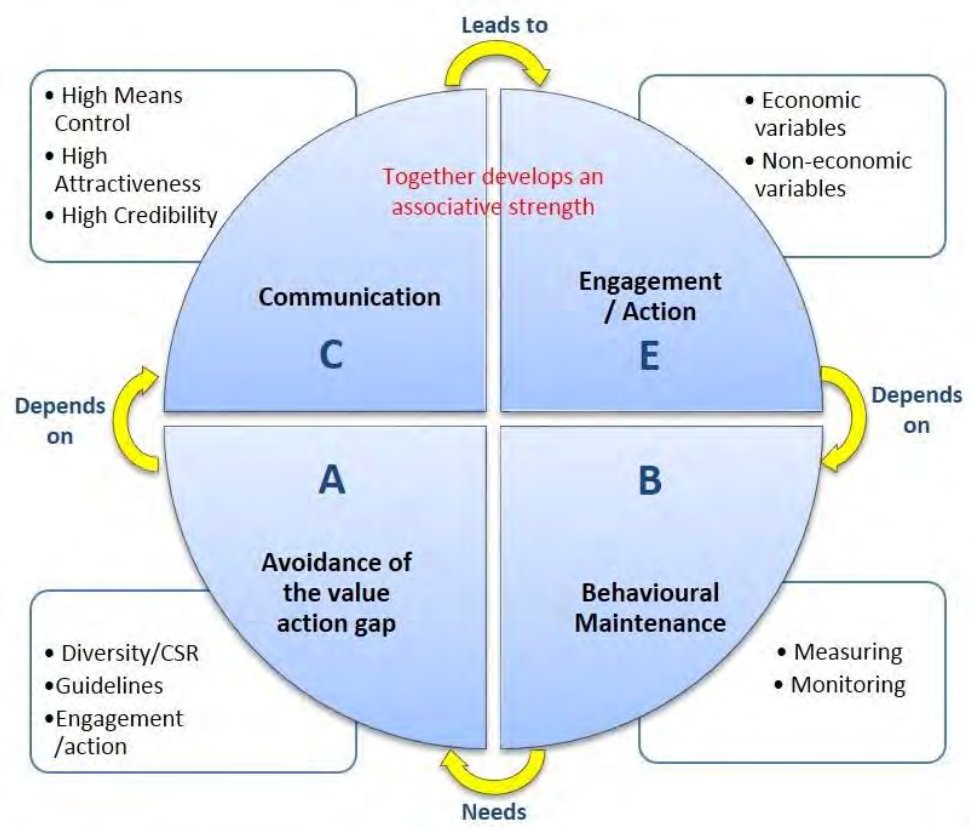

Figure 5: The successive pro-environmental framework (CEBA)

Figure 5 also illustrates how the categories and variables forming the successive pro-environmental framework (CEBA) are interconnected and dependent upon one another.

Firstly, within the category of communication, the variables essential for investigating established normative messages are high means control (mandatory rules and regulations), high attractiveness (feedback and peer pressure), and high credibility (knowledge, information, facts and beliefs).

Secondly, within the engagement/action category, the identified variables essential for investigating factors facilitating the transformation of normative messages into action, in turn enabling development of associative strength, are economic variables (availability of resources) and non-economic variables (social context, situational norm and salient environment).

Thirdly, the behavioural maintenance category enables investigation of the factors that establish a link between a goal and action.

Finally, the category 'avoidance of the value action gap' identifies the mechanisms which are indispensable for avoiding the barriers to encouraging and maintaining behavioural change (misperceptions and pluralistic ignorance).

Investigating re-use behaviour and evaluating the factors facilitating its maintenance is only feasible when each category and its variables is acknowledged and strategically accounted for when applying 
the framework to real-life situations. This is because the categories and variables are interdependent. Therefore, the unavailability of a single category or variable, or the breaking of a single link, can act as a barrier to behaviour change and its maintenance. Depending on the social context, type of organisation, and the type of re-use materials each organisation specialises in, some links (categories and variables) may be more important than others and thus more critical if they are broken.

This successive pro-environmental framework - CEBA - is tested against empirical evidence both as part of the research and in real life scenario with a third sector organisation named The Selby Trust. The former has received recognition from the academic audience through conference presentations (Purohit et al., 2015; Tavri et al., 2014a; Tavri et al., 2014b; Tavri et al., 2015b). The latter, that is; the case study with The Selby Trust was conducted as part of a bursary project, which is published in an academic journal (Tavri et al., 2015a). The finding indicates that CEBA acted as a useful analytical tool in the investigation of the mechanisms and barriers of re-use at the organisational level. It is recommended that the framework can be considered in future pro-environmental behaviour investigations to assess and test its viability for other more extensive areas of environmental behaviour studies.

\section{Limitations}

The successive pro-environmental framework (CEBA) can be viewed as being in the nascent stages, and thus relatively open for further development given that it has only been tested as part of a single research investigation. Nonetheless, since CEBA has been applied in a research for the first time, the findings suggest that CEBA acts as a useful and robust analytical tool to carry out pro-environmental (re-use) behaviour investigations. Furthermore, it is anticipated that the knowledge gathered from this research can be assessed for its applicability in real-life re-use practice.

Because this thesis represents preliminary forays into the applicability of CEBA, both from a theoretical and an empirical viewpoint, it naturally possesses the limitations mentioned above. However, as one of the very few studies in this area, it is believed that the findings create substantial opportunities for further research and study of the implications of approaches to waste management in real-life situations.

\section{References}

Aarts $\mathrm{H}$ and Dijksterhuis Ap (2003) The silence of the library: Environment, situational norm, and social behaviour. Journal of Personality and Social Psychology 84(1):18-28.

Aarts H, Dijksterhuis Ap and Custers R (2003) Automatic normative behaviour in environments: The moderating role of conformity in activation situational norms. Social Cognition 21(6): 447-464.

Ajzen I, and Fishbein M (1980) Understanding attitudes and predicting social behavior. Englewood Cliffs, Prentice-Hall. 
Bargh JA and Ferguson MJ (2000) Beyond behaviorism: on the automaticity of higher mental processes.

Psychological Bulletin 126(6): 925-945.

Barr S, Gilg AW and Ford NJ (2001) A conceptual framework for understanding and analyzing attitudes towards household-waste management. Environment and Planning 33: 2025-2048.

Barr S (2007) Factors influencing environmental attitudes and behaviours: a U.K. case study of household waste management. Environment and Behaviour 39: 435-473.

Bekin C, Carrigan M and Szmigin I (2007) Beyond recycling: 'commons-friendly' waste reduction at new consumption communities. Journal of Consumer Behaviour 6(1): pp.271-286.

Bell PA, Greene TC, Fisher JD and Baum A (2001) Environmental Psychology. Fifth Edition. Wadsworth Group/ Thomson Learning, California.

Berkowitz AD, chapter 1, (2004) The Social Norms Approach: Theory, Research, and Annotated Bibliography. Thesis $(\mathrm{PhD})$, Independent Consultant, Trumansburg.

Brook Lyndhurst Ltd. (2007) Replicating success: Social enterprises and the waste sector in London. London, Brook Lyndhurst.

Budeanu A (2007) Sustainable tourist behavior - a discussion of opportunities for change. International Journal of Consumer Studies 31: 499-508.

Campbell JL (2007) Why would corporations behave in socially responsible ways? An institutional theory of corporate social responsibility. Academy of Management Review 32(3): 946-967.

Cashore B and Vestinsky I (2000) Policy network and firm behaviours: Governance systems and firm responses to external demands for sustainable forest management. Policy Sciences 33: 1-30.

Cialdini RB (2003) Crafting normative messages to protect the environment. Association for Psychological Science 12: 105-109.

Cialdini RB, Demaine LJ, Sagarin BJ, Barrett DW, Rhoads K and Winter PL (2006), Managing social norms for persuasive impact. Social Influence 1(1): 3-15.

Cialdini RB, Reno, RR and Kallgren, CA (1990) A focus theory of normative conduct: Recycling the concept of norms to reduce littering in public places. Journal of Personality and Social Psychology 58(6): 1015-1026.

Cleek MA and Leonard SL (1998) Can corporate codes of ethics influence behavior? Journal of Business Ethics 17: $619-630$.

Collier J and Esteban R (2007) Corporate social responsibility and employee commitment. Business Ethics: A European Review 16(1): 19-33.

DEFRA (2015) UK Statistics on Waste. DEFRA, London.

Dewhurst $\mathrm{H}$ and Thomas R (2003) Encouraging sustainable business practices in a non-regulatory environment: A case study of small tourism firms in a UK national park. Journal of sustainable tourism 11(5): 383-403.

Dijksterhuis Ap, Aarts H, Bargh JA and Knippenberg AdV (2000) On the relation between associative strength and automatic behaviour. Journal of Experimental Social Psychology 36: 531-544.

Dijksterhuis Ap and Bargh JA (2001) The Perception-Behaviour Expressway: Automatic Effects of Social Perception on Social Behaviour. New York University, New York. 
Dolan P, Hallsworth M, Halpern D, King D, Metcalfe R and Vlaev I (2012) Influencing behaviour: The mindspace way. Journal of Economic Psychology 33: 264-277.

Drucker PF (1999) Change Leaders. See http://www.inc.com/magazine/19990601/804.html (accessed 19/08/2016).

Drucker PF (2001) Management Challenges for the 21st Century. HarperBusiness, California.

Elo S and Kyngas H (2007) The qualitative content analysis process. Journal of Advanced Nursing 62(1): 107115.

Glaser BG and Strauss A (1967) The Discovery of Grounded Theory. Aldine, Chicago.

Global Footprint Network (GFN) (2015) Do we fit on the planet? See

http://www.footprintnetwork.org/en/index.php/GFN/page/world_footprint/ (accessed 15/12/2015).

Gockeritz S, Schultz PW, Rendon T, Cialdini RB, Goldstein NJ and Griskevicius V (2010) Descriptive normative beliefs and conservation behaviour: The moderating roles of personal involvement and injunctive normative beliefs. European Journal of Social Psychology 40: 514-523.

Goldstein NJ, Cialdini RB and Griskevicius V (2008) A room with a viewpoint: using social norms to motivate environmental conservation in hotels. Journal of Consumer Research 53(3): 472-482.

Groot JIM and Steg L (2007) General beliefs and the theory of planned behaviour: The role of environmental concerns in the TPB. Journal of Applied Social Psychology 37(8): 1817-1836.

Kagan RA, Thornton D and Gunningham N (2003) Explaining corporate environmental performance: How does regulation matter? Journal of Law and Society Association 37(1): 51-90.

Kaiser FG, Byrka K, and Hartig T (2010) Reviving Campbell's paradigm for attitude research. Personality and Social Psychology review, 1-17.

Kanter RM (1999) From spare change to real change: The social sector as Beta Site for Business Innovation. Harvard Business Publishing, Harvard.

Kallgren CA, Reno RR and Cialdini RB (2000) A focus theory of normative conduct: When norms do and do not affect behaviour. Society for Personality and Social Psychology 26(8): 1002-1012.

Kelman HC (1958) Compliance, identification, and internalization: Three process of attitude change. The Journal of Conflict Resolution 2(1): 51-60.

Kollmuss A and Agyeman J (2002) Mind the gap: why do people act environmentally and what are the barriers to pro-environmental behaviour? Environmental Education Research 8(3): 239-260.

Kong N, Salzmann O, Steger U and Somers A I (2002) Moving business/industry towards sustainable consumption: The role of NGOs. European Management Journal 20(2): 109-127.

Lachman R, Nedd A and Hinings B (1994) Analyzing Cross-national Management and Organisations. A Theoretical Framework. Management Science, 40(1): 40-55.

Locke K (2001) Grounded Theory in Management Research. Thousand Oaks, Sage, California.

Lindenberg S and Steg L (2007) Normative, gain and hedonic goal frames guiding environmental behaviour. Journal of Social Issues 63(1): 117-137. 
Mannetti L, Pirro A and Livi S (2004) Recycling: Planned and self-expressive behaviour. Journal of Environmental Psychology 24: 227-236.

Marsh D and Stoker G (1995) Theory and Methods in Political Science. Macmillan Press Limited, London.

Mayring P (2000) Qualitative content analysis. Forum: Qualitative Social Research 1(2): 1-7.

Meneses GD and Palacio AB (2005) Recycling behaviour: a multidimensional approach. Environment and Behaviour 37(1): 837-860.

Mills J and Briks M (2014) Qualitative Methodology: A practical guide. Sage publications, Los Angeles.

Monbiot G (2000) Captive state: The corporate takeover of Britain. Macmillan, London.

Nye M and Hargreaves T (2009) Exploring the social dynamics of pro-environmental behaviour changes: A comparative study of intervention processes at home and work. Journal of Industrial Ecology 14(1): 137-149.

Oskamp S, Harrington MJ, Edwards TC and Sherwood D L (1991) Factors influencing household recycling behaviour. Environment and Behaviour 23: 494-519.

Organ DW (1997) Organizational citizenship behavior: It's construct clean-up time. Human Performance 10(2): 85-97.

Organ DW, Podsakoff PM and MacKenzie SB (2006) Organisational citizenship behaviour: Its nature, antecedents and consequences. Sage, USA.

Payne DM and Raiborn CA (2001) Sustainable development: The ethics support the economics. Journal of Business Ethics 32: 157-168.

Peng CJ and Chiu SF (2010) An integrative model linking feedback environment and organisational citizenship behaviour. The Journal of Social Psychology 150(6): 582-607.

Pickett-Baker JP and Ozaki R (2008) Pro-environmental products: Marketing influence on consumer purchase decision. Journal of consumer marketing 25(5): 281-293.

Porter LW and Lawler EE (1968) Managerial attitude and performance. Dorsey Press, Homewood, IL.

Prendergrast J, Foley B, Menne V and Isaac A K (2008) Creatures of Habit? The Art of Behaviour Change. The Social Market Foundation, London.

Prentice DA, and Miller DT (1996) Pluralistic ignorance and the perpetuation of social norms by unwitting actors. Advances in Experimental Social Psychology 28:161-209.

Purohit, R, Tavri, P, and Sayce, S (2015) Content analysis as a successful Built environment research methodology. Presentation of the IBEE conference, 3rd to 4th September 2015, Bath: IBEE, UK.

Rimal, RV and Real K (2003) Understanding the influence of perceived norms on behaviour. Communication Theory 13(2): 84-203.

Robinson GM and Read AD (2005) Recycling behaviour in a London Borough: results from large-scale household surveys. Resources, Conservation and Recycling 45(1): 70-83.

Rothman AJ (2000) Towards a theory-based analysis of behavioural maintenance. Health Psychology 19(1): 6469. 
Schultz PW, Nolan JM, Cialdini RB, Goldstein, NJ and Griskevicius V (2007) The constructive, destructive, and reconstructive powers of social norms. Association for Psychological Science 18: 429-434.

Steg $L$ and Vlek C (2009) Encouraging pro-environmental behaviour: An integrative review and research agenda. Journal of Environmental Psychology 29: 309-317.

Stern PC (2000) Toward a coherent theory of environmentally significant behaviour. Journal of Social Issues 56(3): 407-424.

Tavri P, Sayce S and Hands V (2014a) Developing a theoretical behavioural framework and identifying its association with the UK industry evidence on waste re-use. WIT Transactions on Ecology and The Environment 180: $259-271$.

Tavri, P, Sayce, S, and Hands, V (2014b) Influencing organisation behaviour towards waste re-use. Presentation of the RGS-IBG Annual International Conference, 26th to 29th August 2014, London: RGS-IBG, UK.

Tavri P, Sayce S and Hands V (2015a) Organisational behaviour change towards waste re-use in the UK third sector. International Journal of Computational Methods and Experimental Measurements 3(4): 291-304.

Tavri, P, Sayce, S, and Hands, V (2015b) Determining waste re-use behaviour among UK organisations: A content analysis study. Presentation of the RGS-IBG Annual International Conference, 2nd September 2015, Exeter: RGS-IBG, UK.

Thaler RH and Sunstein CR (2009) Nudge Improving decisions about health, wealth and happiness. Penguin Books, London.

Thogersen J. (2006) Norms for environmentally responsible behaviour: An extended taxonomy. Journal of Environmental Psychology 26: 247-261.

Thogersen J. (2007) Activation of social norms in social dilemmas: A review of the evidence and reflections on the implications for environmental behaviour. Journal of Economic Psychology 28: 93-112.

Thomas DR (2003) A general inductive approach for qualitative data analysis. School of Population, Health, University of Aukland, New Zealand.

Thomas T, Schermerhorn Jr. JR and Dienhart JW (2004) Strategic leadership of ethical behaviour in business. Academy of Management Executive 18(2): 56-66.

Urry J (2011) Climate Change and Society. Polity Press, Cambridge.

Valle POD, Rebelo E, Reis E, and Menezes J (2005) Combining behavioural theories to predict recycling involvement. Environment and Behaviour 37: 364-396.

Vermeir I and Verbeke W (2006) Sustainable food consumption: Exploring the consumer "attitude-behavioral intention" gap. Journal of Agricultural and Environmental ethics 19: 169-194.

Vlek C (2000) Essential psychology for environmental policy making. International Journal of Psychology 35(2): 153-167.

Wenzel M (2005) Misperceptions of social norms about tax compliance: From theory of intervention. Journal of Economic Psychology 26: 862-883.

Zhang D (2011) Organisational citizenship behaviour. PSYCH761, White paper. 